\title{
The effect of Bacillus spores on the actinide source term at the WIPP nuclear waste repository
}

J.S. SWANSON ${ }^{1}$, C. HAZELTON ${ }^{1,2}$, A. NAVARRETTE ${ }^{1}$, M.K. RICHMANN $^{1}$, F.E. STANLEY ${ }^{3}$; LA-UR-20-21284

${ }^{1}$ Los Alamos National Laboratory-Carlsbad Operations; 1400 University Drive/Carlsbad, NM 88220 USA

${ }^{2}$ Texas Tech University/Natural Resources Managment; Box 2125, Lubbock, TX 79409

${ }^{3}$ Lawrence Livermore National Laboratory; 7000 East Ave; Livermore, CA 94550 USA

Bacillus spores have been investigated for their ability to adsorb, transform, and accumulate metals, thus affecting metal solubility and mobility. This study investigated the role of spores from a Bacillus species isolated from radioactive waste on the possible transport of neodymium $(\mathrm{Nd})$, a nonradioactive analog for plutonium(III) and americium(III).

Bacillus sp. WW-6-2 was isolated from a waste drum bound for the Waste Isolation Pilot Plant (WIPP) - a terminal repository for legacy, defense-related nuclear waste, located in a subterranean bedded salt formation. Spores of Bacillus WW-6-2 were exposed to neodymium in solutions of varying salt concentration $(0.15 \mathrm{M}, 2 \mathrm{M}, 4 \mathrm{M})$. At "high" biomass concentrations $\left(\sim 10^{7}\right.$ spores $\left./ \mathrm{ml}\right)$, the amount of $\mathrm{Nd}$ removed from solution at $\mathrm{t}=0$ hours was $74 \%$ at $0.15 \mathrm{M}, 35 \%$ at $2 \mathrm{M}$, and $68 \%$ at $4 \mathrm{M}$ (starting concentration, $\sim 1 \mu \mathrm{M}$ ). However, $\mathrm{Nd}$ gradually dissociated from the spores over time, such that by 48-72 hours, all Nd was back in solution again. At "low" biomass concentrations $\left(\sim 10^{6}\right.$ spores $\left./ \mathrm{ml}\right), \mathrm{Nd}$ solution concentrations were almost indistinguishable from the abiotic controls.

The cause of the apparent desorption and resolubilization of Nd over time has not been determined. It was hypothesized that the release of the organic ligand dipicolinic acid (DPA) from the spores might be responsible, since previous experiments on Bacillus sp. WW-6-2 spores exposed to high salt concentrations resulted in the release of as much as 0.5 $\mathrm{mM}$ DPA. DPA was not detected over the course of this experiment; however, method limitations precluded the detection of the Nd-DPA complex. It is also possible that the $\mathrm{Nd}$ species present in solution were either more soluble or less sorptive under the tested conditions.

These results suggest that Bacillus WW-6-2 spores may affect actinide(III) migration by enhancing solubility rather than by acting as biocolloids. Future work will focus on determining the cause for apparent desorption and whether spores of other Bacillus species isolated from the waste will lead to similar results. 